\title{
Cryptococosis meníngea y el sistema inmune. A Propósito de un Caso
}

\author{
Andrea Catalina Nassar Tobón ${ }^{1}$, Neiby Johana Rivera Rojas ${ }^{1}$, María Angélica Pulido Correa ${ }^{2}$, \\ Laura Alejandra León Rivera² ${ }^{2}$ \\ ${ }^{1}$ Especialista en Neurología Clínica, Hospital Universitario Clínica San Rafael. Bogotá - Colombia. \\ ${ }^{2}$ Residente de Medicina Interna III año, Hospital Universitario Clínica San Rafael, Fundación Universitaria Juan N. Corpas. Bogotá - Colombia.
}

\section{RESUMEN}

Introducción: La cryptococosis es una patología infecciosa en creciente aumento posterior a la aparición del VIH. Sin embargo, su presentación en paciente inmunocompetente es de baja frecuencia. De esta manera, se realiza la descripción de un caso clínico de un paciente masculino quien consulta por cefalea y alteración del estado de conciencia, con documentación en LCR de Cryptococcus neoformans.

Objetivo: Describir las características clínicas, el diagnóstico, la evolución y el tratamiento de un paciente inmunocompetente con meningitis criptocócica.

Método: Se realizó una revisión de la historia clínica y extracción de datos previa firma de consentimiento informado, posteriormente se hizo una busqueda de artículos de revisión bibliográfica en PubMed, SCIELO, ProQuest, usando descriptores de Ciencias de la Salud (DeCs) y términos MeSH: reportes de caso, publicaciones y revisiones. Se usaron artículos comprendidos entre 2006 al 2018.

Resultados: Se documentó la presentación clínica, el diagnóstico, evolución y tratamiento de acuerdo con el manejo dado.

Discusión: Al enfrentarnos a un cuadro de criptococosis meníngea en un paciente inmunocompetente, podemos encontrar una presentación clínica bizarra y poco específica que puede generar confusión al momento del diagnóstico. Las infecciones micóticas son entidades de baja frecuencia, que se ven de forma más frecuente en pacientes con compromiso inmunológico como infección por VIH, uso de corticoesteroides o antecedente de trasplantes, entre otros. Dadas estas características, encontrar infecciones de origen micótico en pacientes inmunocompetentes es de baja prevalencia. Por tal razón es de vital importancia la sospecha diagnóstica ante el cuadro clínico y los hallazgos al examen neurológico con el fin de hacer un diagnóstico certero y dar un tratamiento adecuado. Reportamos el caso clínico de un hombre de 53 años sin antecedentes patológicos conocidos, quien ingresó por cefalea, y alteración de la conducta, a quien se le diagnóstico Cryptococosis meníngea.

Palabras clave: Criptococosis meníngea, meningitis crónica, paciente inmunocompetente, sistema inmune, infecciones del sistema nervioso central.

\section{ABSTRACT}

\section{Meningeal cryptococcosis and the immune system. About a Case.}

Introduction: Cryptococcosis is a growing infectious disease after the appearance of HIV. However, its presentation in immunocompetent patients is of low frequency. In this way, the description of a clinical case of a male patient who consulted for headache and altered state of consciousness was made, with documentation in CSF of Cryptococcus neoformans.

Objective: Describe the clinical characteristics, diagnosis, evolution, and treatment of an immunocompetent patient with cryptococcal meningitis.

Method: A review of the clinical history and data extraction was carried out after signing the informed consent, then a search was made for bibliographic review articles in PubMed, SCIELO, ProQuest, using Health Sciences descriptors (DeCs) and MeSH terms: reports reports, publications and reviews. Articles from 2006 to 2018 were used.

Results: The clinical presentation, diagnosis, evolution and treatment were documented according to the management given.

Discussion: When faced with a meningeal cryptococcosis in an immunocompetent patient, we can find a bizarre and unspecific clinical presentation that can generate confusion at the time of diagnosis. Fungal infections are low-frequency entities, which are seen more frequently in patients with immune compromise such as HIV infection, use of corticosteroids or a history of transplants, among others. Given these characteristics, finding fungal infections in immunocompetent patients is of low prevalence. For this reason, it is vitally important to suspect the diagnosis of the clinical picture and the findings of the neurological examination in order to make an accurate diagnosis and provide adequate treatment. We report the clinical case of a 53-year-old man with no known pathological history, who was admitted with headache and behavioral disturbance, who was diagnosed with Cryptococcosis meningea.

Keywords: Meningeal cryptococcosis, chronic meningitis, immunocompetent patient, immune system, central nervous system infections.

\section{*Autor de correspondencia: Nassar Tobón Andrea Catalina andrea-nassar@juanncorpas.edu.co}

Como citar: Nassar Tobón, A., Rivera Rojas, N., Pulido Correa, M., \& León Rivera, L. (2021). Cryptococosis meníngea y el sistema inmune. A Propósito de un Caso. Revista Cuarzo, 27(1), 45-57.

Recibido: 15 de mayo de 2021 Aceptado: 1 de junio de 2021 Publicado: 30 de junio de 2021 Doi: https://doi.org/10.26752/cuarzo.v27.n1.518 


\section{INTRODUCCIÓN}

L A criptococosis es una enfermedad infecciosa con distribución mundial y una amplia gama de presentaciones clínicas causadas por levaduras encapsuladas patógenas del género Cryptococcus. Estos patógenos son hongos basidiomicetos, distribuidos ampliamente en la naturaleza, sin embargo, dos especies especialmente se ven relacionadas de forma más frecuente con infecciones en humanos: Cryptococcus neoformans $y$ Cryptococcus gattii (1).

El Cryptococcus neoformans, se identificó por primera vez como patógeno humano a fines del siglo XIX, pero no se reconoció como una causa común de enfermedad humana, hasta fines de la década de 1970 (1).

En las últimas décadas esta infección se ha expandido de forma exponencial, siendo de gran importancia a nivel mundial, con hasta 1 millón de nuevos casos por año y una importante morbimortalidad atribuibles al aumento de pacientes con infección por el virus de la inmunodeficiencia humana (VIH) y SIDA (2). Aunque el C. neoformans y el C. gattii comparten muchas características de una levadura altamente evolucionada, estas tienen importantes diferencias específicas de especies y cepas con respecto a la distribución geográfica, los nichos ambientales, la predilección del huésped y las manifestaciones clínicas tanto en huéspedes inmunodeprimidos, como en inmunocompetentes.

El $95 \%$ de las infecciones generadas por cryptococo son producidas por el C. neoformans (serotipo A), el 4\% a 5\% restante por el C. neoformans serotipo B o el C. gattii $(1,2)$.

Se ha visto alrededor del mundo la asociación del C. neoformans con la exposición a excremento de aves como palomas y carroñeros, así como insectos como chinches o árboles huecos; la exposición a eucaliptos y árboles tropicales y subtropicales se relaciona con el C. gattii $(1,2)$.

El diagnóstico se da por medio del aislamiento del Cryptococcus, y se puede realizar de dos formas: histopatológico a través de tinción India ink o serológico con detección de anticuerpos en fluidos corporales como suero o líquido cefalorraquídeo $(\mathrm{LCR})(1,2)$.

Una vez se confirme el diagnóstico, se debe dar tratamiento en fase de inducción por dos semanas con anfotericina $\mathrm{B}+$ flucitosina y continuidad con fluconazol $(1,2)$.

De esta manera es poco frecuente encontrar un huésped inmunocompetente sin ningún factor de riesgo para cryptococosis, por lo que nos enfocaremos en la presentación clínica de este grupo poblacional, haciendo énfasis, en las características inmunológicas, las manifestaciones clínicas, el diagnóstico, el tratamiento, y las posibles complicaciones $(1,2)$.

\section{CASO CLÍNICO}

Paciente de 53 años originario de Bogotá, Colombia, sin antecedentes conocidos quien ingresó por cuadro clínico de 1 mes de evolución consistente en cefalea global punzante de intensidad 7/10 no irradiado, antecedido de desviación de la comisura labial izquierda, parestesias ipsilaterales, alteración del comportamiento, dado por agitación psicomotora, heteroagresión, hipersexualidad y somnolencia. Al ingresó se observó paciente agresivo, desorientado y con estado fluctuante de conciencia con tendencia a la somnolencia, por lo que requirió manejo en el área de reanimación, con administración inicial de midazolam y haloperidol sin contención del mismo por lo que se administró infusión de Propofol.

Al examen físico de ingreso con tensión arterial de 110/69 $\mathrm{mmHg}$, frecuencia cardíaca de 58 latidos por minuto, frecuencia respiratoria de 17 por minuto, saturación $100 \%$ con oxígeno 2 litros por minuto y temperatura $36.2^{\circ} \mathrm{C}$. $\mathrm{Al}$ examen neurológico somnoliento, desorientado en espacio y tiempo, disártrico con lenguaje incoherente, sin evidencia de afectación de pares craneanos, fuerza conservada en las 4 extremidades, reflejos musculo tendinosos $2 / 4$, retiraba al dolor de forma simétrica ante el estímulo doloroso, coordinación de difícil valoración por alteración en la esfera mental, no signos meníngeos. Con paraclínicos de ingreso: hemograma, ácido láctico, electrolitos y glucosa dentro de límites normales; VIH, metabolitos para cocaína, benzodiacepinas y atropínicos negativos, creatinquinasa total en 3359 U/L. Radiografía de tórax sin evidencia de consolidaciones o nódulos (imagen 1).

\section{Imagen 1: Radiografía Simple de Tórax: Sin evidencia de consolidaciones o nódulos.}

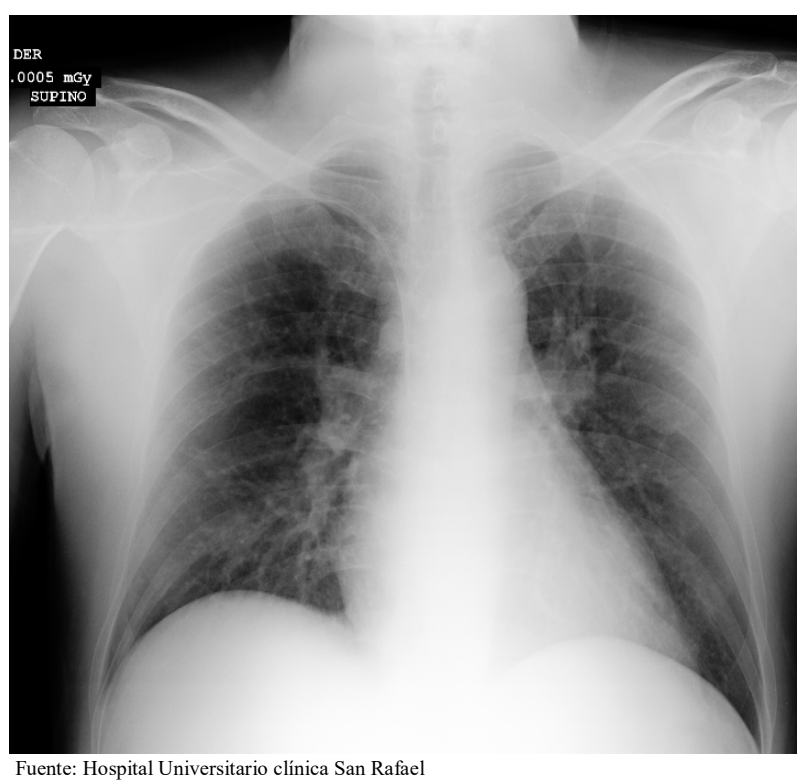

Tomaron resonancia magnética cerebral (RM) simple (imagen 2 y 3), que evidenció signos de retracción cortical sin otras 
anormalidades ni realces patológicos.

Se observa corte coronal con información T2 (imagen 2), y corte axial con información FLAIR (imagen 3), que evidencia signos de retracción cortical.

Imagen 2: RM de Cerebro Simple.

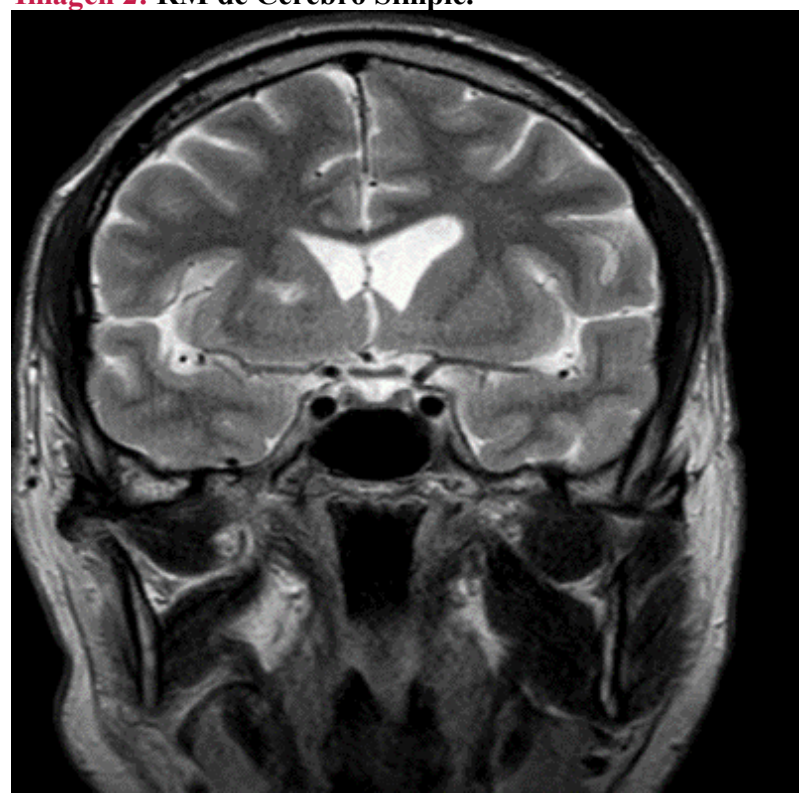

Fuente: Hospital Universitario Clínica San Rafael

Imagen 3: RM de Cerebro Simple.

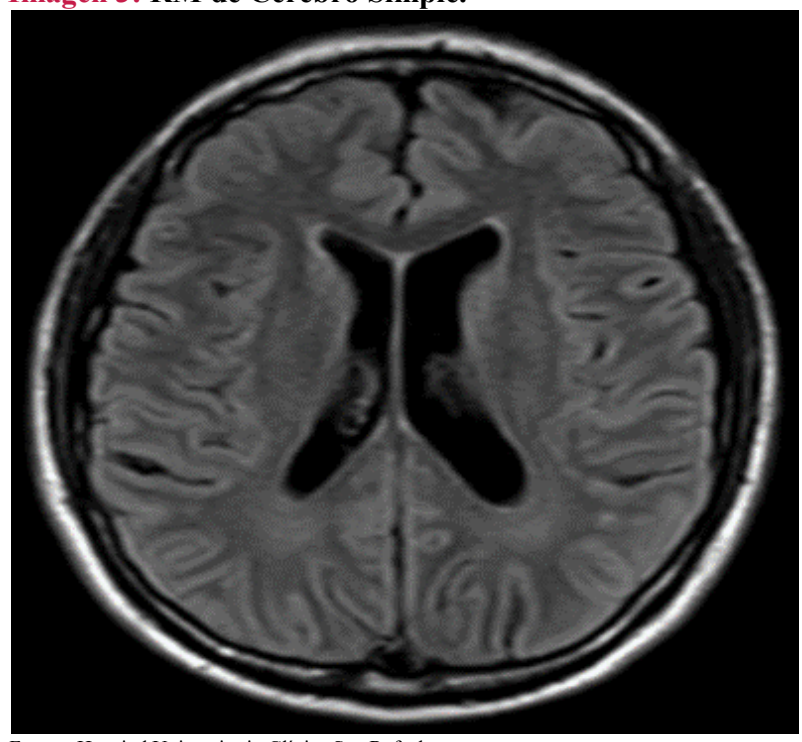

Fuente: Hospital Universitario Clínica San Rafael

Posteriormente se realizó punción lumbar con presión de apertura de $36 \mathrm{~cm}$ de $\mathrm{H} 2 \mathrm{O}$ indicativa de hipertensión endocraneana secundaria, presencia de pleocitosis linfocitaria con hiperproteinorraquia sin consumo de glucosa, PCR para herpes tipo I y II negativo, ADA negativo, Film array de LCR negativo para antígenos bacterianos, con tinta china positivo para levaduras encapsuladas y látex positivo para criptococo (Tabla 1 e imagen 4).
Tabla 1: Descripción de Punción Lumbar con Líquido Cefalorraquídeo.

\begin{tabular}{|c|c|c|c|}
\hline \multirow[b]{2}{*}{ Prueba } & \multicolumn{3}{|c|}{ PL } \\
\hline & (Ingreso) & $\begin{array}{l}\text { (15 días de } \\
\text { periodo de } \\
\text { inducción) }\end{array}$ & $\begin{array}{l}\text { (29 días de } \\
\text { periodo de } \\
\text { inducción) }\end{array}$ \\
\hline $\begin{array}{l}\text { Presión de } \\
\text { apertura }\end{array}$ & $26 \mathrm{cmH} 2 \mathrm{O}$ & $32 \mathrm{cmH} 2 \mathrm{O}$ & $20 \mathrm{cmH} 2 \mathrm{O}$ \\
\hline Aspecto & Límpido & Incoloro & Incoloro \\
\hline Glucosa & $42 \mathrm{mg} / \mathrm{dl}$ & $23 \mathrm{mg} / \mathrm{dl}$ & $32.1 \mathrm{mg} / \mathrm{dl}$ \\
\hline Proteínas totales & $60.3 \mathrm{mg} / \mathrm{dl}$ & $48.5 \mathrm{mg} / \mathrm{dl}$ & $60.2 \mathrm{mg} / \mathrm{dl}$ \\
\hline Color & Claro cristalino & Claro cristalino & Claro cristalino \\
\hline Aspecto & Límpido & Incoloro & Incoloro \\
\hline Leucocitos & $\begin{array}{l}120 / \mathrm{mm} 3 \\
\text { predominio } \\
\text { linfocitos } 75 \%\end{array}$ & $\begin{array}{l}28 / \mathrm{mm} 3 \\
\text { predominio } \\
\text { linfocitos } 90 \%\end{array}$ & $\begin{array}{l}18 / \mathrm{mm} 3 \\
\text { predominio } \\
\text { linfocitos } 100 \%\end{array}$ \\
\hline Hematíes & $\begin{array}{l}13 / \mathrm{mm} 3 \\
\text { Frescos } 100 \%\end{array}$ & $\begin{array}{l}2 / \mathrm{mm} 3 \\
\text { Frescos } 100 \%\end{array}$ & $\begin{array}{l}3 / \mathrm{mm} 3 \\
\text { Frescos } 100 \%\end{array}$ \\
\hline Gram & Blastoconidias & $\begin{array}{l}\text { No se observaron } \\
\text { gérmenes }\end{array}$ & $\begin{array}{l}\text { No se } \\
\text { observaron } \\
\text { gérmenes } \\
\end{array}$ \\
\hline КОН & Levaduras & $\begin{array}{l}\text { No se observaron } \\
\text { estructuras } \\
\text { fúngicas }\end{array}$ & $\begin{array}{l}\text { No se } \\
\text { observaron } \\
\text { estructuras } \\
\text { fúngicas } \\
\end{array}$ \\
\hline Tinta china & $\begin{array}{l}\text { Presencia } \\
\text { levadura } \\
\text { encapsulada }\end{array}$ & $\begin{array}{l}\text { Negativo para } \\
\text { levadura } \\
\text { encapsulada }\end{array}$ & $\begin{array}{l}\text { Negativo para } \\
\text { levadura } \\
\text { encapsulada }\end{array}$ \\
\hline VDRL & No reactivo & No reactivo & No reactivo \\
\hline $\begin{array}{l}\text { Látex para } \\
\text { cryptococo } \\
\text { cualitativo }\end{array}$ & Positivo & Positivo & Positivo \\
\hline Cultivo & C. neoformans & C. neoformans & Negativo \\
\hline $\begin{array}{l}\text { Adenosin } \\
\text { deaminasa }\end{array}$ & Negativo & Negativo & Negativo \\
\hline Ziehl-nielsen & - & Negativo BAAR & - \\
\hline $\begin{array}{l}\text { PCR } \\
\text { Mycobacterium }\end{array}$ & - & Negativo & - \\
\hline $\begin{array}{l}\text { Cultivo } \\
\text { Mycobacterium }\end{array}$ & - & $\begin{array}{l}\text { Negativo a las } 8 \\
\text { semanas }\end{array}$ & $\begin{array}{l}\text { Negativo a las } 8 \\
\text { semanas }\end{array}$ \\
\hline
\end{tabular}

Imagen 4: Levadura encapsulada, bajo tinción de tinta china, vista desde microscopia electrónica: Se observan levaduras encapsuladas y látex positivo para criptococo.

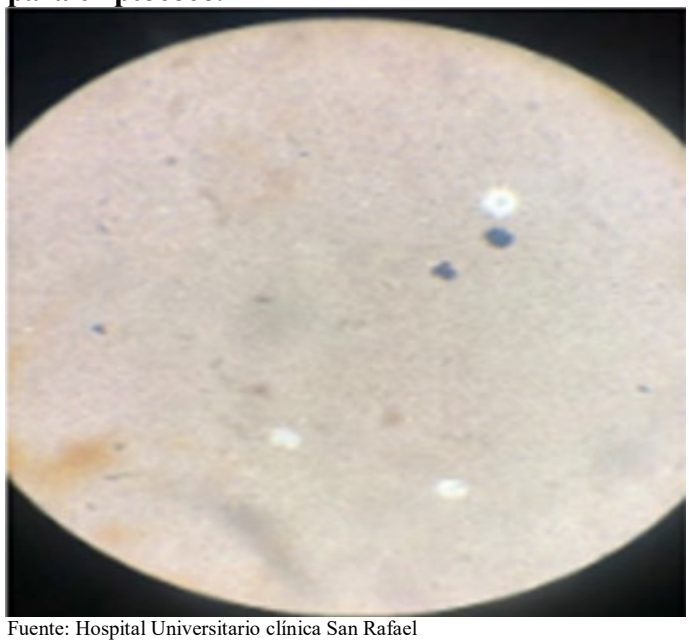


Se realizó carga viral para VIH no detectable. Con la documentación de criptococosis meníngea se inicia manejo con anfotericina B, más flucitosina inicialmente por 15 días, segunda punción lumbar (Tabla 1) de control con persistencia de látex para criptococo positivo y tinta china más $\mathrm{KOH}$ presencia de levaduras encapsuladas por lo que se prolongó 15 días, más fase de inducción. Última punción lumbar (Tabla 1) de control con descenso de presión de apertura y ausencia de tinta china y $\mathrm{KOH}$ para levaduras, se da egreso para dar continuidad al tratamiento con fluconazol $400 \mathrm{mg}$ cada 12 horas por 10 semanas, luego continuar fluconazol $200 \mathrm{mg}$ cada día hasta completar 1 año. Paciente evoluciono hacia la mejoría, adecuada respuesta y tolerancia al tratamiento instaurado.

\section{DISCUSIÓN}

Introducción. La infección por criptococo sigue siendo la etiología fúngica más común de la meningitis crónica en todo el mundo. El Cryptococcus neoformans tiene una distribución global y se encuentra en suelos contaminados, excrementos de aves y en la corteza de los árboles. En particular, los pacientes inmunocompetentes tienen riesgo de meningitis crónica por Cryptococcus gattii y los pacientes sin compromiso por VIH se encuentra de forma más frecuente en hombres jóvenes, aunque tienden a ser ligeramente mayores (2).

Se ha identificado brotes por este germen en Columbia Británica y el noroeste del Pacífico (3). El Centros para el Control y Prevención de de Enfermedades (CDC) de Estados Unidos, estima que en regiones con una carga significativa del virus de inmunodeficiencia humana (VIH)/SIDA, la meningitis criptocócica es un factor importante que contribuye la morbimortalidad, con al menos 100.000 muertes al año, solo en África subsahariana (4); cerca de una tercera parte de los casos a nivel mundial corresponden a Latinoamérica, donde Brasil y Colombia tienen la mayor incidencia con 1001 a 2500 casos, dando una incidencia anual en Colombia de 2.4 casos por 10 habitantes (5).

Lo más frecuente es que los pacientes con VIH presenten un deterioro clínico más rápido que aquellos que no lo padecen, debido al alto riesgo de progresión temprana al coma y a la muerte secundaria a la hipertensión endocraneana (PIC).

El tratamiento rápido y repetido para disminuir la PIC, así como el tratamiento antimicótico dirigido son esenciales en todos los pacientes. Desafortunadamente, a pesar del tratamiento antimicótico, los estudios continúan mostrando tasas de mortalidad de al menos del 25 al 30\% (4). Otras formas de inmunosupresión son factores de riesgo importantes para padecer meningitis criptocócica, incluidos el trasplante, la neoplasia maligna y la linfocitopenia CD4 + idiopática (6).

\section{Agentes etiológicos: Cryptococcus neoformans y Cryptococcus gattii}

El Cryptococcus es un género de hongos basidiomicetos con más de 30 especies distribuidas de forma extendida en el medio ambiente. Se conoce en la actualidad que existe 2 especies que se sabe que causan enfermedades humanas, C. neoformans y C. gattii. El C. neoformans, causa enfermedad tanto en hospedadores inmunodeprimidos como en inmunocompetentes, por su lado el C. gattii, se ha considerado históricamente como un patógeno de pacientes aparentemente inmunocompetentes. Sin embargo, las condiciones preexistentes y los estados de inmunosupresión, incluidos los defectos inmunitarios subclínicos, también se informan como factores de riesgo de infección por esta especie. Estas diferencias de presentación clínica puede que estén relacionados con variables del hospedador, así como por características de los subtipos moleculares del germen.

Históricamente, el género se clasificó en 3 variedades, 5 serotipos (según las diferencias estructurales en la cápsula de polisacárido) y 8 subtipos moleculares (Tabla 2). Sin embargo, se han propuestos algunos cambios taxonómicos, basados en la comprensión de los estudios moleculares obtenidos en la actualidad. Se han propuesto las siguientes divisiones: C. neoformans variedad grubii (serotipo A) con 3 genotipos (VNI, VNII, VNB); C. neoformans variedad neoformans (serotipo D o VNIV); y otras 5 especies crípticas, C. gattii, C. bacillisporus, C. deuterogattii, C. tetragattii y C. decagattii (serotipos B/C o VGI-IV) (7). Los análisis filogenéticos, combinados con una heterogeneidad reconocida con respecto a la virulencia, la preferencia del huésped y la susceptibilidad antifúngica proporcionan evidencia para apoyar clasificación taxonómica adicional en un esquema de 7 especies/4 especies híbridas (Tabla 3). La taxonomía molecular de las especies criptocócicas es un área vibrante de evolución que ha permitido una mayor comprensión de las características específicas de la cepa, incluyendo aptitud y predilección por determinados nichos ambientales. Para esta revisión se manejará la clasificación histórica, C. neoformans y C. gattii.

Tabla 2: Clasificación actual de especies patógenas de Cryptococcus.

\begin{tabular}{lll}
\hline \hline \multicolumn{3}{c}{ Clasificación actual de especies patógenas de Cryptococcus } \\
\hline \hline Serotipos & $\begin{array}{l}\text { Especies y } \\
\text { variedades }\end{array}$ & Tipos moleculares \\
\hline A & $\begin{array}{l}\text { C. neoformans } \\
\text { variedad, Grubii }{ }^{a} .\end{array}$ & VN I, VN II \\
\hline B & C. gattii. & VG I, VG II, VG III, VG IV \\
\hline C & C. gattii. & VG I, VG II, VG III, VG IV \\
\hline D & $\begin{array}{l}\text { C. neoformans } \\
\text { variedad } \\
\text { neoformans. }\end{array}$ & VN IV \\
\hline AD & C. neoformans. & VN III \\
\hline
\end{tabular}

$\overline{{ }^{2} \text { Responsable de la gran mayoría de las enfermedades causadas por C. neoformans en todo el mundo }}$. Adaptado de Hagen F, Khayhan K, Theelen B, et al. Reconocimiento de siete especies en Cryptococcus complejo de especies de gatti / Cryptococcus neoformans. Fungal Genet Biol 2015; 78: 17 
Tabla 3: Clasificación actual de especies patógenas de Cryptococcus.

\begin{tabular}{lcl}
\hline \multicolumn{1}{c}{ Cambios de taxonomía propuestos para el complejo } \\
\multicolumn{1}{c}{ C. neoformans y C. gattii }
\end{tabular}

El C. neoformans se encuentra en todo el mundo en asociación con excrementos de ciertas aves como palomas, carroñeros ambientales como ameba y cochinillas de la humedad y en una variedad de especies de árboles. El C. gattii se asocia comúnmente con varias especies de eucaliptos en climas tropicales y subtropicales, así como árboles de clima templado, como abetos y robles.

El ciclo de vida del Cryptococcus involucra tanto formas asexuales como sexuales (4). La forma asexual es la levadura encapsulada haploide que se reproduce por mitosis con gemación de base estrecha y se encuentra en muestras clínicas y ambientales. La forma sexual, se produce por la meiosis entre 2 tipos de apareamiento (MATa y MAT $\alpha$ ) para formar conexiones, basidios y basiodiosporas. Se cree que el apareamiento del mismo sexo entre 2 cepas del mismo tipo $(\mathrm{MAT} \alpha-\mathrm{MAT} \alpha)$ produce las esporas infecciosas que causan la infección humana.

Epidemiología. Previo al debut de la pandemia del SIDA, la criptococosis se consideraba una infección poco común. Fue un gigante de la micosis que genero gran impacto en la década de 1970 porque se asoció, no solo con inmunodeficiencia adquirida, sino también con malignidad, trasplante de órganos y ciertos tratamientos inmunosupresores. La incidencia de la enfermedad aumentó significativamente a mediados de la década de los años 80, y el VIH/SIDA representó más del 80\% de los casos de criptococosis en todo el mundo $(9,10)$. La meningitis criptocócica se presenta preferentemente en personas con alteración de la inmunidad mediada por células y es una importante infección oportunista relacionada con el SIDA (sobre todo en aquellas personas donde el recuento de células CD4 + cae por debajo de 100 células / $\mu \mathrm{L}$ ).

En la actualidad, gracias a la terapia antirretroviral (TAR) exitosa, la incidencia de criptococosis asociada al VIH ha disminuido significativamente, aunque la incidencia en otras poblaciones en riesgo no ha cambiado (Tabla 4). Aunque tanto el C. neoformans como el C. gattii pueden causar enfermedad en hospedadores aparentemente inmunocompetentes, el porcentaje de infecciones por el C. gattii en estos pacientes es significativamente mayor que para el C. neoformans.

Tabla 4: Factores de riesgo de infección por Cryptococcus.

\begin{tabular}{ll}
\hline \hline \multicolumn{1}{c}{ Factores de riesgo de infección por Cryptococcus } \\
\hline \hline Infección por VIH. & $\begin{array}{l}\text { Enfermedades reumatológicas } \\
\text { como el Lupus eritematoso } \\
\text { sistémico, Artritis reumatoide }\end{array}$ \\
\hline $\begin{array}{l}\text { Terapia con corticoides o } \\
\text { inmunosupresoras. }\end{array}$ & $\begin{array}{l}\text { Linfopenia idiopática de CD4+ } \\
\text { Trasplante de órgano sólido. }\end{array}$ \\
\hline $\begin{array}{l}\text { Enfermedades linfoproliferativas y } \\
\text { malignidad. }\end{array}$ & $\begin{array}{l}\text { Falla renal o/y diálisis } \\
\text { peritoneal. }\end{array}$ \\
\hline Sarcoidosis & $\begin{array}{l}\text { Síndrome de Hiper IgM/Hiper } \\
\text { IgE }\end{array}$ \\
\hline $\begin{array}{l}\text { Tratamiento con anticuerpos } \\
\text { monoclonales (etanercept, infliximab, } \\
\text { alemtuzumab) }\end{array}$ & Diabetes Mellitus \\
\hline Anticuerpos anti-GM CSF & \\
\hline \hline Adaptado de Casadevall A, Perfect JR. Cryptococcus neoformans. Washington, DC: ASM Press; 1998.
\end{tabular}

Patogénesis. La primoinfección se presenta por vía respiratoria al ingresar la levadura al alvéolo, de esta manera el macrófago alveolar genera la primera respuesta inmunológica, que es la del huésped, generando una activación de células $\mathrm{T}$ ayudadoras con producción de citoquinas proinflamatorias, factor de necrosis tumoral (FNT), interferón G e interleucina 2, resultando inflamación granulomatosa. De esta manera las levaduras inactivas (pero viables) que está en los ganglios torácicos y los granulomas pulmonares pueden permanecer asintomáticos durante años (11).

Cuando el sistema inmunológico se suprime por algún motivo la activación de células $\mathrm{T}$ ayudadoras, la levadura se disemina saliendo de los ganglios linfáticos torácicos, generando una reactivación local, para posteriormente diseminarse al ser fagocitada por macrófagos logrando acceso a otros sistemas (11). Su paso al sistema nervioso central (SNC) es por transcitosis de la levadura libre a través de la barrera hematoencefálica o transportadose medio de los macrófagos con el mecanismo de "caballo de troya" (11).

El C. neoformans tiene 3 factores de virulencia predisponentes dados por la formación de cápsula, la producción de pigmento de melanina y la termo tolerancia. Tiene una cápsula 
polisacárida antifagocítica, compuesta por glucuronoxylomannan, única en las especies de Cryptococcus y con múltiples efectos en la inmunidad del hospedero. Adicionalmente el $\mathrm{C}$. neoformans produce una enzima catalizadora de compuestos difenólicos para la formación de melanina, dando una capacidad de proteger la levadura del estrés oxidativo lo que explica al neurotropismo del patógeno, finalmente la capacidad de aumentar la temperatura a $37^{\circ}$ o más con múltiples vías de señalización y enzimas que ha adquirido o adaptado con el fin de mejorar su patogénesis en mamíferos. Otros factores de virulencia son la producción de fosfolipasa, ureasa, y la presencia de otras enzimas que la protegen del estrés oxidativo, dándole la capacidad de sobrevivencia a los fagolisosomas. De esta forma se adapta de forma sofisticada y escapa del ambiente intracelular generando un fenómeno de exocitosis, con la capacidad de pasar de célula a célula sin lesionar los fagocitos (11).

Se ha identificado múltiples factores de virulencia del Cryptococcus, los tres factores de virulencia clásicos y prominentes de C. neoformans incluyen la formación de cápsulas, la producción de pigmento de melanina y la termotolerancia (14). El C. neoformans posee una enzima que cataliza la conversión de difenólicos compuestos para formar melanina, que al expresarse pueden tener un papel biológico para proteger las levaduras del estrés oxidativo del huésped, lo que puede explicar parcialmente el neurotropismo del organismo en sitios con altas concentraciones de catecolaminas difenólicas. Finalmente, la capacidad de crecer a $37^{\circ} \mathrm{C}$ es una parte básica del compuesto de virulencia (4).

Otros factores de virulencia incluyen la producción de fosfolipasa, ureasa y múltiples enzimas asociadas con la protección contra el estrés oxidativo, lo que confiere supervivencia dentro del fagolisosoma (4).

La levadura incluso ha adaptado mecanismos sofisticados para escapar del entorno intracelular modificando la permeabilidad de la membrana del fagosoma y mediante exocitosis no lítica (vomocitosis), lo que permite la transferencia de la levadura de célula a célula o del compartimento del huésped y sus factores de virulencia sin dañar los macrófagos del huésped (4).

De su patogénesis, podemos mencionar que la exposición a este germen es frecuente, y el individuo inmunocompetente sano es generalmente resistente a la enfermedad criptocócica. Se ha documentado en este grupo la presencia de anticuerpos antifactor estimulante de colonias de macrófagos de granulocitos como un defecto inmune potencial para evitar la infección. La respuesta inmune efectiva es a través de un apoyo de células $T$ colaboradoras. Desde macrófagos activados y no macrófagos alternativos hasta el desarrollo de anticuerpos protectores sobre anticuerpos no protectores, la inmunidad cambia durante el curso de las infecciones criptocócicas. El Cryptococcus produce enfermedad cuando la inmunidad es demasiado pequeña o excesiva, pero cuando la inmunidad del huésped humano es la correcta, por lo habitual, la enfermedad no aparece.

Manifestaciones clínicas. El C. neoformans y C. gattii tienen una gran predilección por establecer una enfermedad clínica en los pulmones y en el SNC. Otros sitios corporales de infección menos frecuentes incluyen piel, próstata, ojos, huesos y articulaciones. Sin embargo, este germen en condiciones de inmunosupresión severa infecta la mayoría de los órganos en pacientes, por lo que tiene la capacidad de aparecer en cualquier sitio del cuerpo humano.

Infección pulmonar. El tracto respiratorio es la puerta de entrada más importante para Cryptococcus. En este caso puede ser tanto asintomático como sintomático. En el primer caso se genera la colonización asintomática de las vías respiratorias, se logra identificar por la presencia de radiografía de tórax anormal, que muestra la presencia de la formación de un nódulo pulmonar simple, en los casos sintomáticos los pacientes pueden presentar una neumonía potencialmente mortal con la presencia de un síndrome de dificultad respiratoria aguda. De hecho, los hallazgos radiológicos más frecuentes de la criptococosis incluyen nódulos no calcificados e infiltrados pulmonares, únicos o múltiples, bien definidos, derrames pleurales, linfadenopatía hiliar y cavitación pulmonar. Lo habitual, es que los pacientes con inmunosupresión, la neumonía criptocócica suele ser sintomática $y$, en algunos casos, puede progresar rápidamente a un síndrome de dificultad respiratoria aguda, incluso en ausencia de afectación del SNC. La afectación pulmonar oscila entre el $10 \%$ al $55 \%$ de los pacientes con meningoencefalitis criptocócica asociada a SIDA, aunque los síntomas del SNC suelen predominar en el cuadro clínico (15).

La prueba del antígeno polisacárido criptocócico en suero suele ser negativa en casos de criptococosis pulmonar aislada verdadera, pero a veces puede ser positiva en ausencia de afectación del SNC u otros sitios aparentes de infección (4). Sin embargo, en individuos inmunodeprimidos con Cryptococcus aislado del pulmón u otro órgano, se debe considerar una punción lumbar para descartar compromiso del SNC independientemente de los síntomas del paciente o de los resultados del título de antígeno sérico. La única situación en la que puede que no se requiera necesariamente una punción lumbar de detección es un paciente con Cryptococcus aislado del pulmón en el paciente aparentemente inmunocompetente sin síntomas atribuibles a compromiso del SNC.

\section{Infección del sistema nervioso central}

Las manifestaciones en SNC pueden ser muy extensas, empezando por cefalea, fiebre, neuropatía craneal, alteración del estado de conciencia, pérdida de memoria, letargo, signos de irritación meníngea, etre otros. El cuadro puede ser insidioso llegando a durar varios días o semanas, y es por ello que es uno de las posibilidades de diagnóstico etiológico de las meningitis subagudas y crónicas. Se ha encontrado que individuos con concentraciones en LCR de $1 ` 000.000$ levaduras/ \mm》^3, 
títulos más altos de antígeno para Cryptococcus en LCR o presión de apertura elevada tienen cuadros de más corta duración (4).

En un estudio realizado en Colombia por Lizarazo y Cols, en donde revisan 90 casos de pacientes con diagnóstico de Criptococosis meníngea, el 70\% estaba asociado a infección por $\mathrm{VIH}$, y el 30\% restante fueron pacientes sin VIH. El 88.9\% de los pacientes sin VIH no tenían ningún factor de riesgo conocido. Se encontró que las manifestaciones clínicas más frecuentes en pacientes VIH seronegativos fueron las alteraciones visuales y las manifestaciones extraneurales, así como la hipertensión endocraneana, sin hidrocefalia; igualmente se observaron cambios al examen neurológico en todos los pacientes seronegativos y la evolución de los síntomas fue mayor (44.1 días vs. 19.3 días, $\mathrm{p}<0.001$ ) (16).

Se documentó en los pacientes sin factores de riesgo, que tenían alteraciones más marcadas en los hallazgos de LCR como lo son la hipoglucorraquia y la hiperproteinorraquia, así como un aislamiento en cultivo de LCR de C. neoformans en el $40 \%$ de esta población y $60 \%$ de C. Gattii (16).

Dado que es un cuadro de meningitis subagudo o crónico se deben tener en cuenta otro tipo de infecciones asociadas de origen micótico como el Histoplasma, Blastomyces, Coccidioides immitis, Coccidioides posadasii, Aspergillus y Candida. Si es de origen viral la infección primaria por VIH, Citomegalovirus, Virus del Herpes simple tipo 1 (HSV-I) y tipo 2 (HSV-2), Poliovirus, Enterovirus, Virus de la Coriomeningitis linfocítica y Paramyxoviridae; de causa bacteriana por Treponema pallidum y Mycobacterium tuberculosis, Nocardia, Leptospira, Brucella y Listeria monocytogenes; de forma menos frecuente los parasitarios como el Echinococcus, Strongyloides, Acanthamoeba, Angiostrongylus, Taenia solium, Baylisascaris y Toxoplasma gondii. Además, se debe tener en cuenta la meningitis no infecciosa secundaria a enfermedades autoinmunes, inflamatorias, neoplásicas $\mathrm{o}$ vasculíticas (4).

La gravedad de la enfermedad está determinada principalmente por factores inmunes del huésped, el compromiso de diferentes especies y/o cepas de Cryptococcus. Por ejemplo, en ciertas áreas del mundo, se ha observado que C. gattii causa criptococomas cerebrales o hidrocefalia con o sin grandes masas pulmonares con mayor frecuencia que el C. neoformans (17).

Los pacientes con afectación del parénquima cerebral pueden tener una presión intracraneal elevada y cursar con neuropatías craneales. En tales pacientes, en ocasiones, es requerido el manejo quirúrgico temprano, pues es probable que tengan pobre respuesta al manejo anti-fúngico.

La criptococosis puede presentarse asintomáticamente en el huésped inmunocompetente, lo que lleva al retardo en el diagnóstico, consecuentemente al retraso en el tratamiento y al desarrollo de importantes secuelas neurológicas.

El C. gattii es una levadura relacionada con casos en individuos previamente sanos; En el noroeste del Pacífico los brotes se han asociado más con enfermedad pulmonar (18).

Se ha documentado que durante las infecciones humanas, el Cryptococcus, utiliza la lacasa, una enzima perteneciente al grupo de las oxidasas de cobre azul, y que además genera una virulencia neurotrópica con factor oxidante de neurocatecolaminas dentro de los tractos dopaminérgicos, particularmente los ganglios basales, lo que parece explicar, el porqué de la propensión al compromiso de las regiones subcorticales en lugar del compromiso frontal. Presentaciones como alteración del estado de conciencia, convulsiones o signos de meningitis basilar, incluyendo la enfermedad de pseudoMéniére, puede ocurrir; en ausencia de fiebre, estas presentaciones hacen que el diagnóstico de la enfermedad criptocócica sea difícil. Las neuropatías craneales que afectan por lo general, lo nervios craneales II a VIII son poco comunes y pueden estar en relación con el aumento de la presión intracraneal manifestada por edema de papila, invasión fúngica directa o inflamación. El compromiso visual, la pérdida auditiva, el deterioro cognitivo y la ataxia de la marcha con o sin incontinencia urinaria puede acompañar la hidrocefalia de obstructiva o no obstructiva y puede ser de larga duración, especialmente después de retrasos en el diagnóstico.

Diagnóstico. Es de vital importancia realizar un diagnóstico adecuado, se puede hacer de dos formas: histopatológico y serológico. Uno de los métodos de diagnósticos más utilizados corresponde a la evaluación directa con tinción india ink, constituye la técnica más rápida para el diagnóstico de meningitis criptocócica es microscopía directa. En este se observa de forma directa las levaduras encapsuladas mediante preparación de LCR con tinta china. El Cryptococcus se puede visualizar como una levadura encapsulada globular con o sin gemación, que varía en tamaño de 5 a $20 \mathrm{~mm}$ de diámetro. La sensibilidad de la tinción con tinta china en LCR depende de la carga fúngica y se informa que es del $30 \%$ al $50 \%$ en personas con infección no relacionada con SIDA y hasta un $80 \%$ en enfermedades relacionadas con SIDA. Falsos positivos puede resultar de linfocitos intactos, otras células de tejido y formas de levadura no viables, que limita aún más la utilidad diagnóstica de la microscopía directa de LCR para criptococos.

El Cryptococcus puede identificarse mediante tinción histológica de tejidos del pulmón, piel, médula ósea, cerebro y otros órganos. La tinción de Fontana-Masson identifica la melanina en la pared celular de la levadura. La tinción de metenamina de Gomori plata, que tiñe la pared celular de los hongos, también se utiliza para identificar el organismo a partir de datos clínicos.

El diagnóstico de criptococosis mejoró significativamente con el desarrollo de pruebas serológicas. Las técnicas de aglutinación de látex e inmunoensayo enzimático disponible ampliamente (utilizando suero y LCR), pueden alcanzar una 
sensibilidad y especificidad general del $93 \%$ a $100 \%$ y $93 \%$ a $98 \%$, respectivamente $(20,21)$. Los falsos negativos pueden verse debido a un efecto prozona en el contexto de antígenos con titulos extremadamente altos, que pueden superarse con dilución (21).

Pacientes con baja carga fúngica, como en casos de meningitis crónicas de bajo grado o en las primeras etapas de la infección, y muestra inadecuada también puede causar resultados falsos negativos en las pruebas de aglutinación de látex.

Recientemente, se aprobó un ensayo de flujo lateral para su uso en suero y LCR, con sensibilidad y especificidad de más del $98 \%$ en ambos tipos de muestras y una sensibilidad del $85 \%$ en la orina (22).

Los títulos de antígeno de polisacárido criptocócico basal en suero y LCR se correlacionan con carga fúngica y tienen importancia pronóstica en pacientes con meningitis por criptococo. La actividad fungicida eficaz se ha correlacionado con el éxito de los regímenes antimicóticos, incluida la supervivencia (4).

A pesar de una década de uso y validación de su eficacia en estudios clínicos, el uso de cultivo cuantitativo de levadura en LCR para la determinación de actividad fungicida eficaz aún no se ha convertido en parte de la rutina clínica práctica.

El líquido cefalorraquídeo (LCR) en la meningitis criptocócica se caracteriza por la presencia de pleocitosis linfocitaria, aumento de la proteína y bajos niveles de glucosa. En pacientes con meningitis criptocócica que están inmunodeprimidos, el perfil de LCR puede ser insípido con un recuento de glóbulos blancos y proteínas en LCR casi normales (4). El cultivo de hongos es muy sensible y puede ser útil tanto para el diagnóstico de infección como para la identificación de microorganismos, aunque el crecimiento del cultivo puede ser lento y producir resultados falsos negativos. El rendimiento diagnóstico aumenta cuando se analiza gran cantidad de LCR, especialmente en casos con una baja carga fúngica. El antígeno criptocócico en el LCR es muy sensible y específico, por lo que se recomienda como la prueba primaria para diagnosticar rápidamente los casos de meningitis criptocócica.

La prueba del antígeno criptocócico en suero no deben usarse para descartar meningitis criptocócica, aunque la detección del antígeno criptocócico en suero puede ser útil en poblaciones de alto riesgo, ya que es detectable unas pocas semanas antes del inicio de los síntomas neurológicos (4).

\section{Imágenes en infección por Cryptococo}

El C. neoformans es un organismo ubicuo que causa infección en el hombre, tanto en individuos inmunodeprimidos como inmunocompetentes. Se sabe que el organismo produce enzimas que permiten lisar el revestimiento pial y causar infiltración parenquimatosa (24).

En un estudio realizado por Zhe-Ren Tan en el 2016, donde se evaluaron 18 pacientes inmunocompetentes, quienes contaban con reportes de resonancia magnética, se observaron hallazgos anormales en 16 pacientes. Los hallazgos documentados fueron la presencia de lesiones intraparenquimatosas con o sin realce, compromiso prominente de los ganglios basales, distribución miliar de nódulos parenquimatosos, múltiples espacios de Virchow-Robin dilatados y realce leptomeníngeo. Seis pacientes tenían ventriculomegalia. En este estudio, los hallazgos intraparenquimatosos fueron más comunes que el realce leptomeníngeo y lesiones perivasculares.

En este mismo estudio, se pudo observar que la resonancia de cerebro con contraste mostró realce lineal e hiperintensidades parciales en secuencias con información T2/FLAIR del parénquima cerebral a nivel del lóbulo occipital y el cuerpo calloso, y así como edema parenquimatoso (imagen 4,5,6,7).

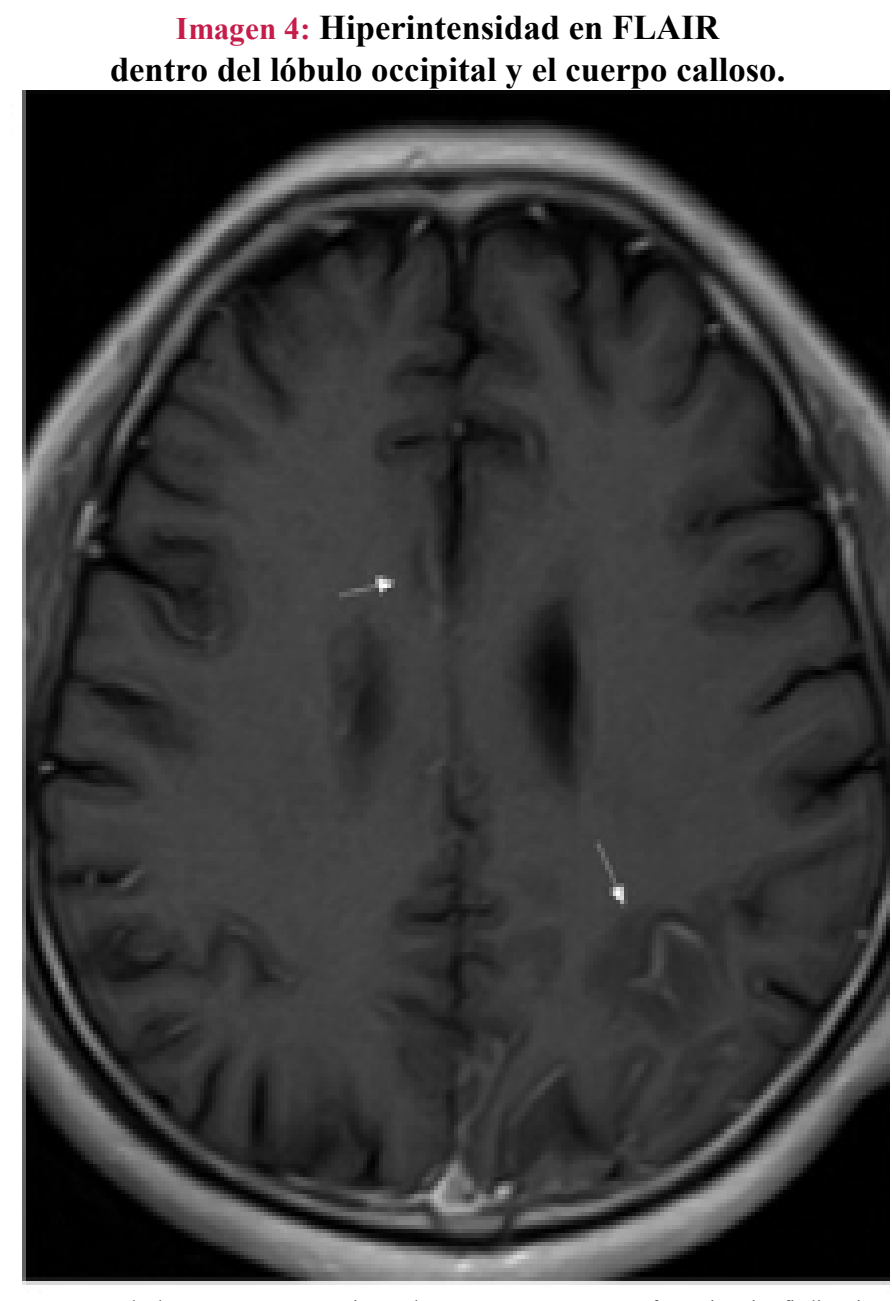

Fuente: Tomado de Tan ZR, Long XY, Li GL, Zhou JX, Long L. Spectrum of neuroimaging findings in cryptococcal meningitis in immunocompetent patients in China - A series of 18 cases. J Neurol Sci 
Imagen 5: Se observa hiperintensidad en FLAIR dentro del lóbulo occipital y el cuerpo calloso.

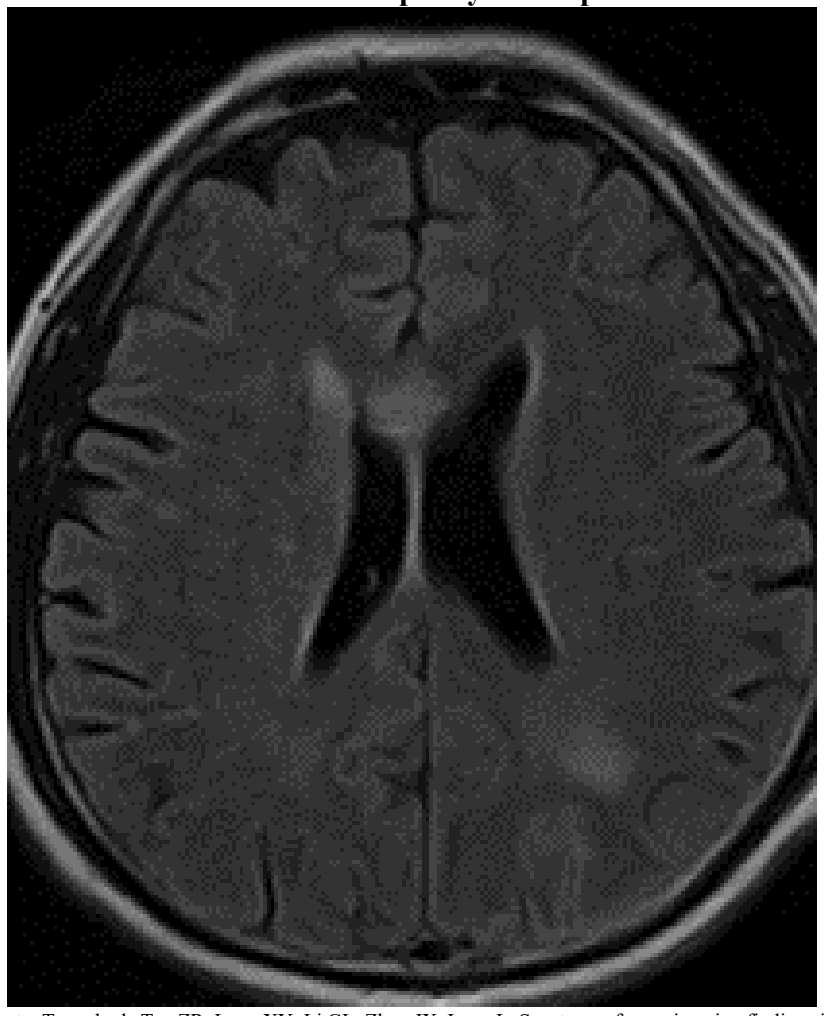

Fuente: Tomado de Tan ZR, Long XY, Li GL, Zhou JX, Long L. Spectrum of neuroimaging findings in cryptococcal meningitis in immunocompetent patients in China - A series of 18 cases. J Neurol Sci.

Imagen 6: Múltiples lesiones hiperintensas en parches bilaterales en $\mathrm{T} 2$ en los ganglios basales

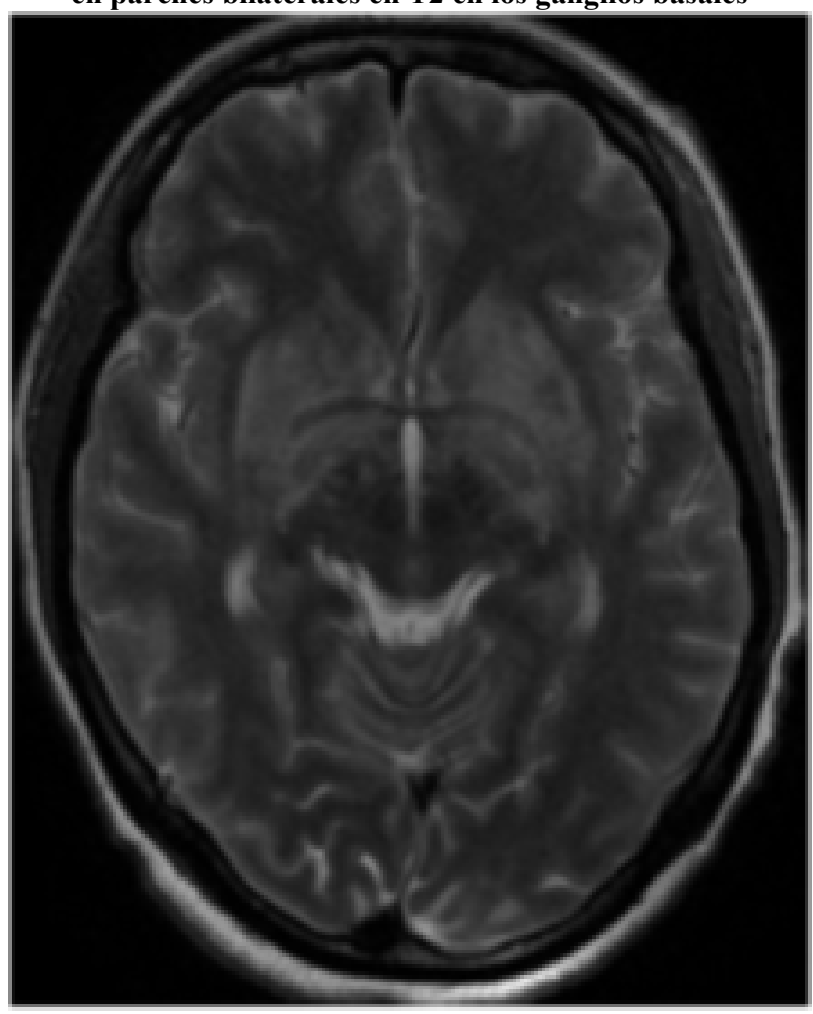

Fuente: Tomado de Tan ZR, Long XY, Li GL, Zhou JX, Long L. Spectrum of neuroimaging findings in cryptococcal meningitis in immunocompetent patients in China - A series of 18 cases. J Neurol Sci.
Imagen 7: Imagen axial en $\mathrm{T} 1$ con contraste

muestra realces puntuales en el cerebelo.

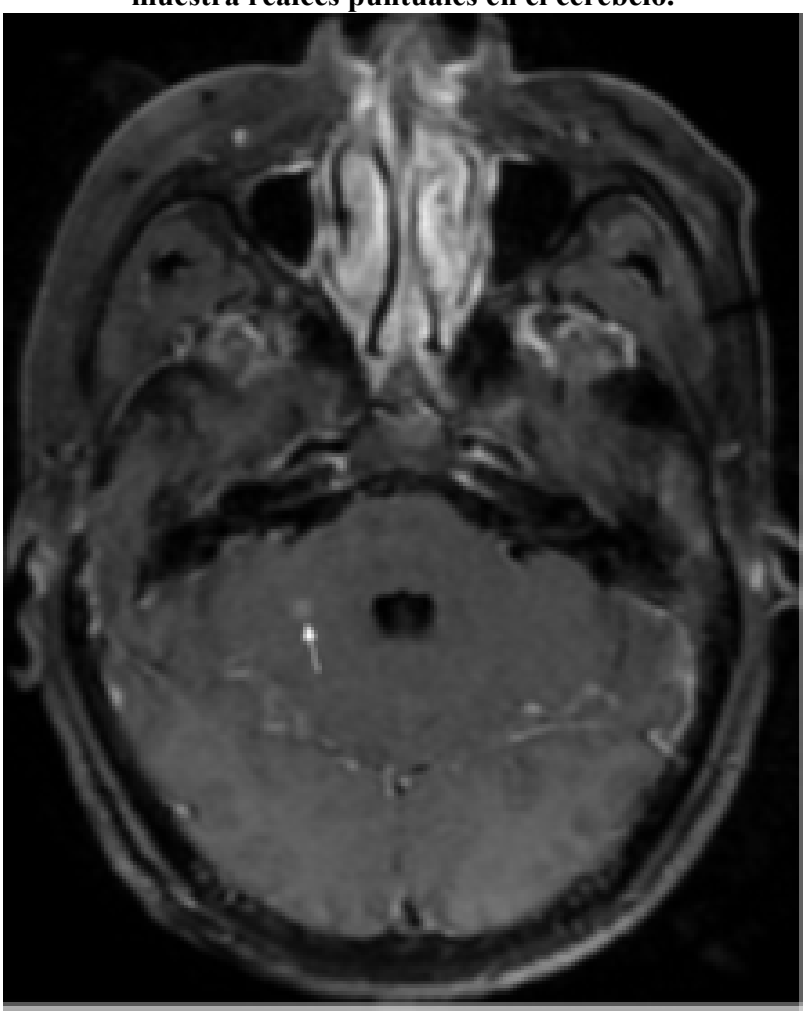

Fuente: Tomado de Tan ZR, Long XY, Li GL, Zhou JX, Long L. Spectrum of neuroimaging findings in cryptococcal meningitis in immunocompetent patients in China - A series of 18 cases. J Neurol Sci.

Otra de las lesiones que se pueden presentar son los criptococomas representan una respuesta de hipersensibilidad parenquimatosa a los hongos (23).

Algunos pacientes con infección por criptococosis pueden presentar infartos cerebrales agudos, que muestran señales en difusión (Imagen 8).

Imagen 8: Imagen hiperintensa a nivel ganglio basal izquierda en secuencia FLAIR, con restricción en las imágenes de difusión.
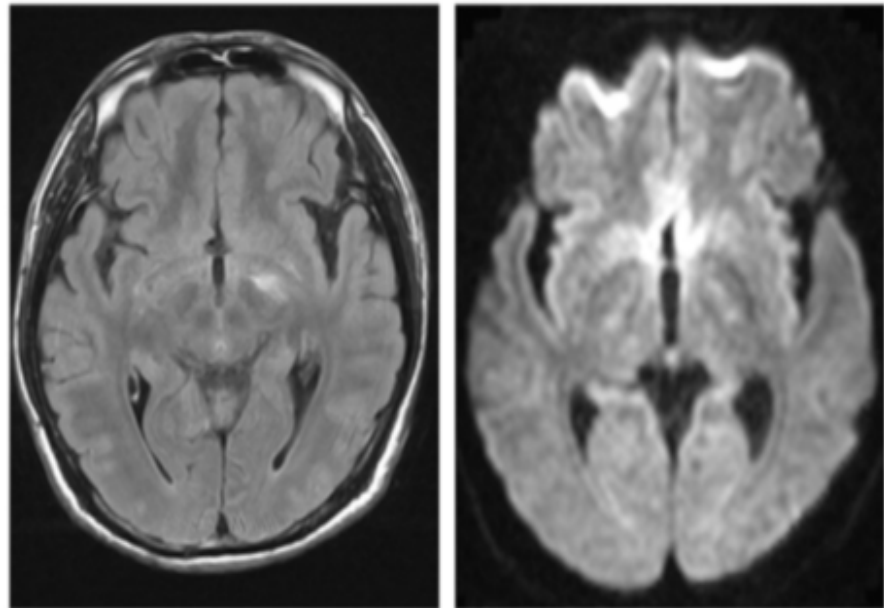

Tomado de Tan ZR, Long XY, Li GL, Zhou JX, Long L. Spectrum of neuroimaging findings in cryptococcal meningitis in immunocompetent patients in China - A series of 18 cases. J Neurol Sci. 
Otras de las lesiones descritas son la presencia de Espacios dilatados de Virchow-Robin en ganglios basales y sustancia blanca periventricular (Imagen 9).

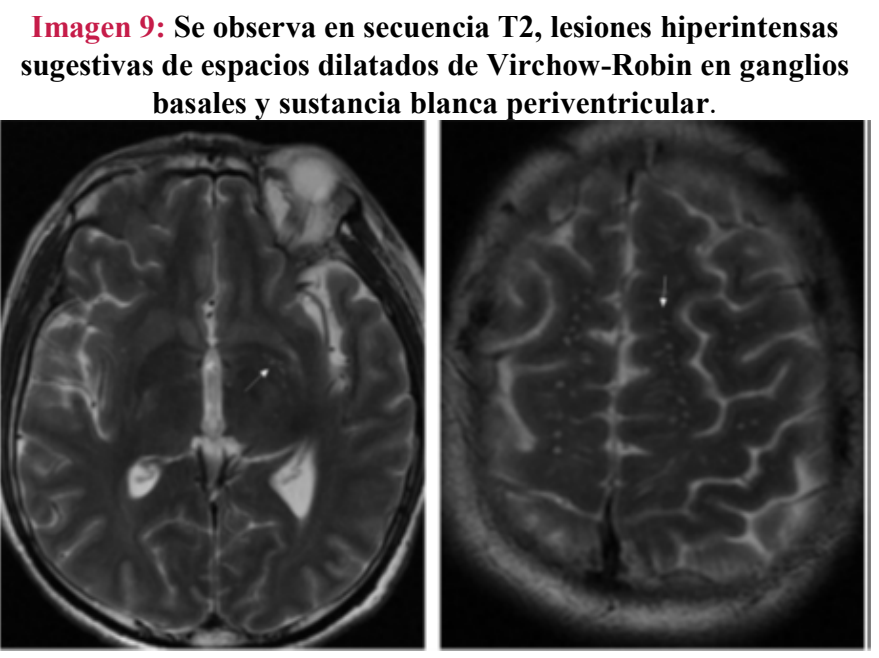

Fuente: Tomado de Tan ZR, Long XY, Li GL, Zhou JX, Long L. Spectrum of neuroimaging findings in cryptococcal meningitis in immunocompetent patients in China - A series of 18 cases. J Neurol Sci.

Así mismo en la Meningitis por Cryptococcus se puede observar la presencia de realce meníngeo, en un estudio realizado por Sarkis RA et al en el 2015, con 19 pacientes, el $74 \%$ de estos tenían resultados anormales en las imágenes de RM de cerebro con contraste. En este estudio los pacientes con infección por Cryptococo sin estado de inmunosupresión asociado a VIH se documentó que casi el $60 \%$ de los pacientes que recibieron contraste mostraron realce leptomeníngeo. Dos de esos pacientes, con realce nodular, sugestivo de granulomas $\mathrm{y}$, potencialmente, una respuesta inflamatoria robusta a diferencia de la respuesta observada en pacientes VIH positivos. Se piensa comúnmente que la meningitis es una meningitis basilar. La afectación leptomeníngea puede provocar hiperintensidad $\mathrm{T} 2$ reactiva extensa en el parénquima adyacente.

Imagen 10: Se observa en las imágenes de T1 con contraste, realce leptomeníngeo y quiste hipocampal posterior derecho.

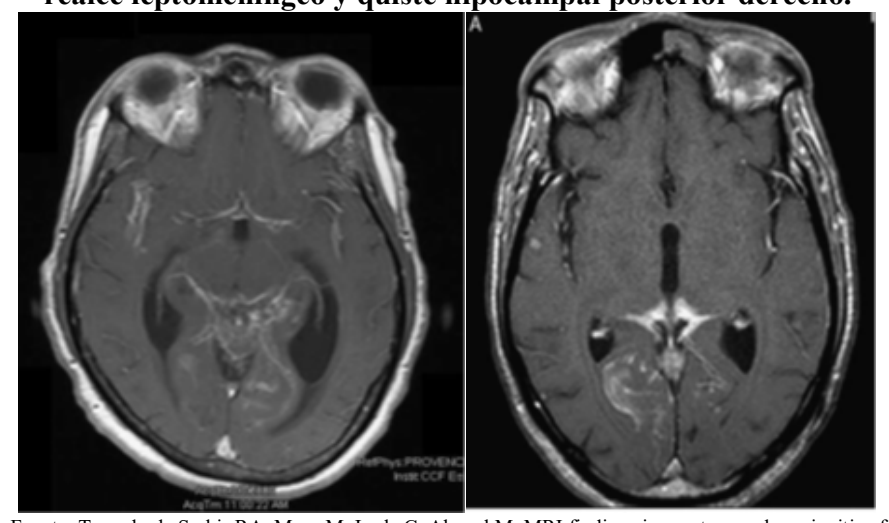

Fuente: Tomado de Sarkis RA, Mays M, Isada C, Ahmed M. MRI findings in cryptococcal meningitis of the non-HIV population. Neurologist. 2015.
El criptococo como primoinfección pulmonar se puede observar en la radiografía de tórax con la presencia de nódulos no calcificados e infiltrados pulmonares, derrame pleural, linfadenopatías hiliares y cavitaciones pulmonares.

Tratamiento. El manejo de la criptococosis se establece con desoxicolato de anfotericina $\mathrm{B}$ (AmBd), el cual constituye el manejo principal del tratamiento de la criptococosis grave, incluida la meningoencefalitis (Tabla 5). Se recomienda una dosis de inducción estándar de 0,7 a $1 \mathrm{mg} / \mathrm{kg} / \mathrm{día}$. La anfotericina B liposomal (3-6 mg/kg/d) se ha convertido en una alternativa preferida con resultados similares y de menor nefrotoxicidad, y se recomienda específicamente para la inducción primaria en pacientes con riesgo de disfunción renal. La flucitosina (5-FC) se usa en combinación terapia con AmBd como terapia de primera línea en la meningitis criptocócica o criptococosis pulmonar a dosis de $100 \mathrm{mg} / \mathrm{kg} /$ día en dosis divididas. La combinación representa el régimen fungicida más potente, con una esterilización del LCR más rápida y menos recaídas, y se asocia con una menor mortalidad atribuible (4). Al combinarlo representa un régimen de tratamiento más potente. La interrupción del tratamiento está relacionada con pobres desenlaces con aumento de la mortalidad (1-6).

La falla terapéutica temprana, se caracteriza por la persistencia de antígeno y cultivo para cryptococo positivo en LCR después de 14 días de fase de inducción, motivo por el que se debe repetir en los siguientes 14 días y realizar nuevamente estudio de LCR (25).

Aunque la terapia de inducción combinada sigue siendo la primera línea recomendada para la criptococosis grave, la disponibilidad de 5-FC es limitada en entornos donde las tasas de la enfermedad es alta y mortalidad son las más altas.

Terapias de combinación alternativas se han investigado; la más eficaz es AmBd más fluconazol ( $800 \mathrm{mg} /$ día), lo que resulta en mejores tasas de eliminación de hongos, recuperación neurológica, y supervivencia en comparación con AmBd solo o en combinación con dosis más bajas de fluconazol. Esta combinación ofrece una opción más factible y potencialmente viable para una terapia inicial eficaz en entornos donde el acceso al 5-FC es limitado.

No se recomienda la monoterapia con fluconazol para la meningitis, dado que la inducción dada su naturaleza fungistática, escaso éxito y mayores tasas de recaída, así como mayores tasas de resistencia en la recaída. Sin embargo, en áreas sin acceso a AmBd, deben comenzarse dosis altas (1200 $\mathrm{mg} / \mathrm{d}$ ) de fluconazol.

Un régimen de 3 etapas de inducción, consolidación y mantenimiento es el tratamiento estándar para la meningitis criptocócica en todos los pacientes, independientemente de los factores de riesgo del huésped. 
Se han sugerido en la meningoencefalitis por C. gattii, independientemente del estado inmunológico del huésped, debido a la gravedad observada de la enfermedad neurológica en este grupo de pacientes, en general debe tratarse de manera similar C. neoformans.

Después de la consolidación, la supresión a largo plazo se inicia con fluconazol oral (200 a $400 \mathrm{mg} /$ día). Este enfoque ha disminuido las tasas de recaída de aproximadamente el $40 \%$ a menos del $5 \%$ en pacientes gravemente inmunosuprimidos (26).

La profilaxis secundaria se interrumpe después de 1 a 2 años de tratamiento antifúngico en pacientes. Los otros triazoles (itraconazol, voriconazol y posaconazol) son activos contra cepas criptocócicas in vitro $\mathrm{y}$, en combinación con $\mathrm{AmBd}$, tienen una actividad fungicida similar a la del 5-FC, pero debido a las diferencias en la biodisponibilidad, penetración del LCR, interacciones farmacológicas, costo y falta de estudios sólidos en criptococosis, estos agentes no se recomiendan como agentes de primera línea para la consolidación o el mantenimiento, sin embargo, pueden tener un papel en los casos refractarios (27).

Una vez culminada esta fase se da continuidad al tratamiento en fase de mantenimiento con fluconazol 200-400 mg/día por largo término. Se ha considerado continuar por 1 o 2 años (4).

Tabla 5: Recomendaciones de tratamiento para la meningoencefalitis criptocócica.

\begin{tabular}{|c|c|}
\hline \multicolumn{2}{|c|}{$\begin{array}{l}\text { Recomendaciones de tratamiento para la meningoencefalitis } \\
\text { criptocócica. }\end{array}$} \\
\hline Terapia de inducción & "Duración \\
\hline \multicolumn{2}{|l|}{ Régimen primario: } \\
\hline $\begin{array}{l}\text { - } \quad \operatorname{AmBd}(0,7 \text { a } 1 \mathrm{mg} / \mathrm{kg} / \text { día }) \text { más flucitosina } \\
(5-\mathrm{FC})(100 \mathrm{mg} / \mathrm{kg} / \mathrm{día})\end{array}$ & 2 semanas. \\
\hline \multicolumn{2}{|l|}{ Régimen alternativo: } \\
\hline $\begin{array}{l}\text { - } \mathrm{Si} \text { el 5-FC es intolerante o no está } \\
\text { disponible: } \mathrm{AmBd}(0,7 \mathrm{a} 1 \mathrm{mg} / \mathrm{kg} / \text { día }) \text { o } \\
\mathrm{L}-\mathrm{AMBc}(3-4 \mathrm{mg} / \mathrm{kg} / \text { día }) \text { o } \mathrm{ABLC}(5 \\
\mathrm{mg} / \mathrm{kg} / \text { día })\end{array}$ & 4 a 6 Semanas. \\
\hline $\begin{array}{l}\text { - AmBd }(0.7-1 \mathrm{mg} / \mathrm{kg} / \mathrm{día}) \text { asociado a } \\
\text { fluconazol }(800 \mathrm{mg} / \mathrm{día})\end{array}$ & 2 semanas. \\
\hline $\begin{array}{l}\text { - Fluconazol ( } 800 \mathrm{mg} / \text { día, de preferencia } \\
1200 \mathrm{mg} / \mathrm{día}) \text { asociado a 5-FC (100 } \\
\mathrm{mg} / \mathrm{kg} / \mathrm{día}) \text {. }\end{array}$ & 6 semanas. \\
\hline $\begin{array}{l}\text { - Fluconazole }(800-2000 \mathrm{mg} / \text { día, de } \\
\text { preferencia } 1200 \mathrm{mg} / \text { día }) .\end{array}$ & \\
\hline - Itraconazole (200 mg dos veces día). & 10 a 12 semanas. \\
\hline \multicolumn{2}{|l|}{ Terapia de consolidación: } \\
\hline - $\quad$ Fluconazol (400 mg/día). & 8 semanas. \\
\hline $\begin{array}{l}\text { Terapia de mantenimiento o supresora: } \\
\text { - Fluconazol ( } 200 \mathrm{mg} \text { / día })\end{array}$ & Más de 1 año. \\
\hline \multicolumn{2}{|l|}{ Regimen Alternativo: } \\
\hline $\begin{array}{l}\text { - } \quad \text { Itraconazole (200 mg dos veces día). } \\
\text { - } \quad \operatorname{AmBd}(1 \mathrm{mg} / \mathrm{kg} \mathrm{IV} \text { por semana). }\end{array}$ & Igual o Más de 1 año. \\
\hline
\end{tabular}

Abreviaturas. 5-FC, flucitosina; ABLC, complejo lipídico de anfotericina B; AmBd, desoxicolato de anfotericina B; BID, dos veces al día; L-AMB, anfotericina B liposomal.
Adaptado de Perfect JR, Dismukes WE, Dromer F, et al. Guías de práctica clínica para el manejo de la enfermedad criptocócica: actualización de 2010 de la Sociedad Estadounidense de Enfermedades Infecciosas. Clin Infect Dis 2010 .

Complicaciones. Una de las principales complicaciones en la meningitis por cryptococo de forma frecuente es el incremento de la presión intracraneana generada por la obstrucción del flujo de salida del LCR secundaria al agrupamiento de levaduras, incrementando la morbilidad y mortalidad en estos pacientes (4). Junto con la optimización de la terapia antifúngica, el manejo del aumento intracraneal; la presión es de importancia crítica en la meningoencefalitis criptocócica.

Las imágenes intracraneales deben realizarse antes de la punción lumbar, sobre todo si hay alteración del estado mental o déficit neurológicos focales están presentes. Se debe obtener la presión de apertura (PA) basal en todos los pacientes. Se debe controlar el aumento de la presión intracraneal cuando los pacientes son sintomáticos, aunque los datos emergentes sugieren que puede ser beneficioso punciones lumbares terapéuticas, independientemente de la presión de apertura inicial en entornos con recursos limitados; de ser necesario en pacientes sintomáticos se recomienda realizar un control estricto de la presión de apertura con punciones lumbares a repetición (diaria o día de por medio), hasta que la PA sea estable durante $>2$ días, inserción de drenaje lumbar, ventriculostomía o derivación ventriculoperitoneal, si se desarrolla hidrocefalia obstructiva.

Se ha recomendado la consulta neuroquirúrgica en casos de meningoencefalitis debido a $\mathrm{C}$. gattii, donde la inflamación del SNC suele ser grave (28).

Tratamientos médicos tales como corticosteroides (a menos que se sospeche de IRIS o en casos de infección grave por C. gattii), por lo general, no se recomiendan, así como el manitol y acetazolamida.

Algunos pacientes presentan meningoencefalitis por C. neoformans persistente, esta es definida como un cultivo positivo a pesar de un mes de tratamiento antimicótico, o la recaída descrita como la presencia de nuevos síntomas y signos clínicos con cultivo positivo posterior de la mejoría clínica y esterilización micótica de LCR. La indicación es reiniciar la fase de inducción por un tiempo más prolongado y con dosis más alta según tolerancia del paciente y complicaciones (4, 26,27).

\section{CONCLUSIÓN}

Es importante tener en cuenta que la cryptococosis meníngea es la neuroinfección micótica más frecuente en nuestro medio, y aunque es una entidad de muy baja incidencia en paciente 
inmunocompetente siempre se debe tener en cuenta como diagnóstico diferencial, para dar un tratamiento rápido y oportuno, con el fin de disminuir las complicaciones, la morbilidad, y la mortalidad.

Conflicto de Intereses: Los autores declaran no tener ningún conflicto de intereses.

\section{Abreviaturas}

FLAIR: Recuperación de inversión atenuada de fluido

PA: Presión de apertura.

LCR: Líquido cefalorraquídeo

RM: resonancia magnética

PIC: hipertensión endocraneana

FNT: factor de necrosis tumoral

CDC: Centros para el Control y Prevención de

Enfermedades.

5-FC: flucitosina

ABLC: complejo lipídico de anfotericina B

AmBd: desoxicolato de anfotericina B

BID: dos veces al día

L-AMB: anfotericina B liposomal.

(VIH)/SIDA: inmunodeficiencia humana

TAR: terapia antirretroviral

IRIS: síndrome de reconstitución inmune

Agradecimientos: Se hace especial mención de agradecimiento al departamento de Medicina Interna, el grupo de docencia e investigación, y a la dirección científica y general del Hospital Universitario Clínica San Rafael.

Consentimiento para publicación: Consentimiento para publicación: Después de obtener el consentimiento informado por escrito por parte del paciente, para la realización del reporte de caso, se sometió al Comité de Ética de investigación del Hospital Universitario Clínica San Rafael. Una copia está disponible para revisión.

Contribuciones de los autores: El manuscrito final, ha sido redactado, revisado y aprobado por todos los autores, quienes participaron en el cuidado del paciente.

Fondos: Esta investigación fue financiada por los investigadores.

\section{REFERENCIAS}

1. Knoke M, Schwesinger G. One hundred years ago: the history of cryptococcosis in Greifswald. Medical mycology in the nineteenth century. Mycoses. 1994;37:229-33.

2. Park BJ, Wannemuehler KA, Marston BJ, et al. Estimation of the current global burden of cryptococcal meningitis among persons living with HIV/AIDS. AIDS 2009;23:525-30.

3. Litvintseva A, Marra R, Nielsen $\mathrm{K}$, et al. Evidence of sexual recombination among Cryptococcus neoformans serotype A isolates in sub-Saharan Africa. Eukaryot Cell. 2003; 2(6):1162-8.

4. Maziarz EK, Perfect JR. Cryptococcosis. Infect Dis Clin North Am. 2016 Mar;30(1):179-206. doi: 10.1016/j.idc.2015.10.006. PMID: 26897067; PMCID: PMC5808417.

5. Thakur K, Wilson M. Chronic Meningitis. CONTINUUM: Lifelong Learning in Neurology. 2018;24(5):1298-1326.

6. Zhu LP, Wu JQ, Xu B, et al. Cryptococcal meningitis in nonHIV-infected patients in a Chinese tertiary care hospital, 19972007. Med Mycol 2010;48(4):570-579. doi:10.3109/13693780903437876. [PubMed: 20392150.

7. Hagen F, Khayhan K, Theelen B, et al. Recognition of seven species in the Cryptococcus gatti/Cryptococcus neoformans species complex. Fungal Genet Biol 2015;78:16-48.

8. Lin X, Hull C, Heitman J. Sexual reproduction between partners of the same mating type in Cryptococcus neoformans. Nature. 2005; 434:1017-21. [PubMed: 15846346]

9. Hajjeh RA, Conn LA, Stephens DS, et al. Cryptococcosis: population-based multistate active surveillance and risk factors in human immunodeficiency virus-infected persons. Cryptococcal Active Surveillance Group. J Infect Dis. 1999; 179:449-54. [PubMed: 9878030]

10. Perfect JR, Casadevall A. Cryptococcosis. Infect Dis Clin North Am. 2002; 16:837-74. [PubMed: 12512184].

11. Firacative, C., Lizarazo, J., Illnait-Zaragozí, M. and Castañeda, E., 2018. The status of cryptococcosis in Latin America. Memórias do Instituto Oswaldo Cruz, 113(7).

12. Galnares-Olalde, J., Loza-Jalil, S., Gómez-Peña, F., MuñozAbraham, O., Pavía-Aubry, V. and de Luna-Gallardo, D., 2014. Criptococosis meníngea en un paciente inmunocompetente: reporte de un caso y revisión de la literatura. Revista Médica Del Hospital General De México, 77(3), pp.137-141.

13. Escandón P, De Bedout C, Lizarazo J, Agudelo C, Tobón Á, Bello $\mathrm{S}$ et al. Criptococosis en Colombia: resultados de la encuesta nacional, 2006-2010. Biomédica. 2012;32(3).

14. Chen S, Sorrell T, Nimmo G, et al. Epidemiology and hostand variety-dependent characteristics of infection due to Cryptococcus neoformans in Australia and New Zealand. Australasian Cryptococcal Study Group. Clin Infect Dis. 2000; 31:499-508. [PubMed: 10987712]

15. Brizendine K, Baddley J, Pappas P. Pulmonary cryptococcosis. Semin Respir Crit Care Med 2011;32(6):72734.

16. Escandón, P., Lizarazo, J., Agudelo, C. and Castañeda, E., 2018. Cryptococcosis in Colombia: Compilation and Analysis of Data from Laboratory-Based Surveillance. Journal of Fungi, 4(1), p.32.

17. Phillips $\mathrm{P}$, Galanis E, MacDougall L, et al. Longitudinal clinical findings and outcome among patients with Cryptococcus gattii infection in British Columbia.Clin Infect Dis 2015;60(9):1368-76

18. Panackal AA, Williamson PR. Fungal Infections of the Central Nervous System. Continuum (Minneap Minn). 2015 Dec;21(6 Neuroinfectious Disease):1662-78. doi: 10.1212/CON.0000000000000241. PMID: 26633781.

19. Antinori S. New Insights into HIV/AIDS-Associated Cryptococcosis. ISRN AIDS 2013;2013:471363.

20. Tanner DC, Weinstein MP, Fedorciw B, et al. Comparison of commercial kits for detection of cryptococcal antigen. J Clin Microbiol 1994;32:1680-4.

21. Wu TC, Koo SY. Comparison of three commercial cryptococcal latex kits for detection of cryptococcal antigen. J Clin Microbiol 1983;18:1127-30.

22. Jarvis JN, Percival A, Bauman S, et al. Evaluation of a novel point-of-care cryptococcal antigen test on serum, plasma and 
urine from patients with HIV associated cryptococcal meningitis. Clin Infect Dis 2011;53:1019-23.

23. Tan ZR, Long XY, Li GL, Zhou JX, Long L. Spectrum of neuroimaging findings in cryptococcal meningitis in immunocompetent patients in China - A series of 18 cases. J Neurol Sci. 2016 Sep 15;368:132-7. doi: 10.1016/j.jns.2016.06.069. Epub 2016 Jul 1. PMID: 27538616.

24. Sarkis RA, Mays M, Isada C, Ahmed M. MRI findings in cryptococcal meningitis of the non-HIV population. Neurologist. 2015 Jan;19(2):40-5. doi: 10.1097/NRL.0000000000000000. PMID: 25607331.

25. Bozette SA, Larsen RA, Chiu J, et al. A placebo-controlled trial of maintenance therapy with fluconazole after treatment for cryptococcal meningitis in the Acquired Immunodeficiency Syndrome. N Engl J Med 1991;324:580-4.

26. Denning DW, Tucker RM, Hanson LH, et al. Itraconazole therapy for cryptococcal meningitis and cryptococcosis. Arch Intern Med 1989;149:2301-8.

27. Franco-Paredes C, Womack T, Bohlmeyer $T$, et al. Management of Cryptococcus gattii meningoencephalitis. Lancet Infect Dis 2015;15:348-55. 